\title{
Receptiveness and preferences of health- related smartphone applications among Vietnamese youth and young adults
}

Toan Thanh Thi Do ${ }^{1}$, Mai Dinh Le ${ }^{2}$, Thanh Van Nguyen ${ }^{1}$, Bach Xuan Tran ${ }^{1,3}$, Huong Thi Le ${ }^{1}$, Hinh Duc Nguyen ${ }^{1}$, Long Hoang Nguyen ${ }^{8}$, Cuong Tat Nguyen ${ }^{*}$, Tho Dinh Tran', Carl A. Latkin ${ }^{3}$, Roger C. M. Ho and Melvyn W. B. Zhang ${ }^{7}$

\begin{abstract}
Background: As smartphone becomes increasingly prevalent and affordable, more youths today can own a smartphone device and download applications in various application stores. Smartphone applications have been proven to be useful for youths in various aspects. However, there has been a paucity of data looking into the preferences of Vietnamese youths and adolescents with regards to health-related applications and their receptiveness towards smartphone apps. Therefore, this study aimed to determine the receptiveness and preferences of healthrelated smartphone applications (mHealth apps) among online Vietnamese youths and adolescents.

Methods: An online cross-sectional study was conducted between the periods of August till October 2015 in Vietnam. Respondent-driven sampling technique (RDS) was utilized to recruit participants. Participants were asked questions about their history of downloading and using health-related smartphone applications and their receptiveness when using these applications. Moreover, socio-demographic characteristics and health status were also self-reported. Multivariate logistic regression was employed to determine associated factors.

Results: Among 1028 participants, 57.4\% owned a smartphone and only $14.1 \%$ of smartphone users have used a health-related smartphone application, and most of these individuals downloaded the applications for disease prevention (66.3\%). 66.4\% of the participants who owned these applications reported that health applications were useful and $92.8 \%$ reported being satisfied with the functionalities of the applications which they owned. Among smartphone users, people who were employed $(\mathrm{OR}=15.46 ; 95 \% \mathrm{Cl}=4.93-48.47)$ were more likely to download mHealth apps. Meanwhile, youths with higher EQ-5D index had a lower likelihood of downloading healthcare-related smartphone applications $(\mathrm{OR}=0.17 ; 95 \% \mathrm{Cl}=0.04-0.81)$.

Conclusions: This study highlighted a low rate of mHealth apps utilization among online Vietnamese youths and adolescents but a high acceptance of individuals who already used these apps. Developing mHealth apps or interventions towards the disease prevention and quality of life improvement could be feasible to proliferate the benefits of such applications in youths and adolescents in Vietnam. Further research should be conducted to optimize the contents and interfaces of mHealth apps that meet the needs of these populations.
\end{abstract}

Keywords: Smartphone applications, Youths, Young adults, Vietnam

\footnotetext{
* Correspondence: bach.jhu@gmail.com; cuong.ighi@gmail.com

'Institute for Preventive Medicine and Public Health, Hanoi Medical

University, Hanoi, Vietnam

${ }^{4}$ Institute for Global Health Innovations, Duy Tan University, Da Nang,

Vietnam

Full list of author information is available at the end of the article
}

(c) The Author(s). 2018 Open Access This article is distributed under the terms of the Creative Commons Attribution 4.0 International License (http://creativecommons.org/licenses/by/4.0/), which permits unrestricted use, distribution, and reproduction in any medium, provided you give appropriate credit to the original author(s) and the source, provide a link to the Creative Commons license, and indicate if changes were made. The Creative Commons Public Domain Dedication waiver (http://creativecommons.org/publicdomain/zero/1.0/) applies to the data made available in this article, unless otherwise stated. 


\section{Background}

Advances in information technology have led to the advent of the smartphone, which has become an integral part of people's lives nowadays. A smartphone is a device on which additional features could be added by means of applications, and it is also a device that runs an operating system that allows for various computing options, and enables individuals to be constantly connected to the World Wide Web [1]. According to the data of The Statistics Portal, the number of smartphone users has been predicted to increase from 1.5 billion in 2014 to about 2.5 billion in 2019 [2]. A more recent statistical report has estimated that as of 2017, there are an estimated 6.5 million applications across all the application stores [3]. Approximately $80 \%$ of smartphone owners in the United States check their phones every $15 \mathrm{~min}$ [4], which implies that individuals are increasingly reliant on these devices to help them in communication, acquisition of information as well as for various other entertainment purposes. Notably, smartphone has a huge number of mobile applications, or "apps", which are software programs that could enhance the inherent functionality of smartphones. The number of health and medical related applications has been estimated to amount to 100,000 to date, with diverse applications catering to a wide variety of conditions ranging from smoking cessation, to that of weight management in the prevention of common chronic diseases. The vast diversity of apps helps to make smartphones more appealing to the masses, especially for the youths and adolescents. Prior studies have indicated that at least one-fifths of smartphone users have downloaded health related applications on their phone [5] and these individuals have used these applications daily [6].

As smartphone becomes increasingly prevalent and affordable, more youths today are able to own a smartphone. A study in Australia in 2013 found that almost $83 \%$ of sampled youths had accessed to smartphone and downloaded an application within the 6 months period [7]. Smartphone could be used to encourage this population to participate in various health and wellness programs $[8,9]$, such as pain management; weight management; assessment of their dietary and caloric intakes as well as in reproductive health promotion [10-14]. However, the usage of health-related apps is low in this group. Prior research indicated that only $24 \%$ of youths owned at least one health-related application and $26 \%$ of them have used health related applications only once [15]. The low uptake rates could be attributed to the diversity of the applications available online, as well as the fact that the current health applications conceptualization does not appeal to the needs of the younger generation.

The growth of economy and the affordability of smartphone have resulted in the significantly increasing number of Vietnamese people owning a smartphone in the recent years. A survey in 2016 estimated that $36 \%$ of the population have had access to a smartphone device, with a higher penetration rate in the urban areas [16]. Most of owners utilized their smartphones for accessing the Internet and social networking sites [16]. However, there has been a paucity of data looking into the preferences of Vietnamese with regards to health-related applications and their receptiveness towards smartphone applications, particularly among young people. Therefore, this study aimed to determine the receptiveness and preferences of health-related smartphone applications (mHealth apps) among Vietnamese youths and adolescents.

\section{Methods}

\section{Study design and sampling technique}

An online cross-sectional study was conducted from August to October 2015 in Vietnam. Participants were recruited if they met the following inclusion and eligibility criteria: a) Aged between 15 to 24 years old, b) Currently residing in Vietnam and c) Having email or social network account to invite their friends/relatives.

Respondent-driven sampling technique (RDS) was utilized to recruit participants. First, we purposively invited several core groups from universities and high schools in Vietnam (Hanoi Medical University, Vietnam National University, Hung Yen high school, and Phan Boi Chau high school) to participate in the study. These groups were selected to reflect the diversity of sample in consideration of their age, gender and level of educations. All participants were required to provide electronic informed consent prior to the commencement of the online questionnaire study. After completing questionnaire, each participant in the core group was asked to recruit up to five peers or relatives via email or other preferred mass media. The survey was terminated when the network was deemed to be unable to expand further.

Participants were required to provide their answers through the Google Form. Double participants were identified through duplication of email (a total of 7 cases). Individuals who did not meet the eligible criteria were excluded (3 cases). We also excluded people who did not answer more than $60 \%$ of the questions in the study. A cumulative total of 1028 participants took part in the online cross-sectional survey.

\section{Web-survey design}

The web-based questionnaire was designed using Google Form. Prior to the commencement of the study, participants were briefly provided information about the purpose of the study, the methodology as well as the information of the principal investigators. The web-based questionnaire consisted of 40 questions, and the participants needed to answer a minimum mandatory number of 23 questions 
about the primary outcomes of this study and basic socio-economic status. Prior to the actual implementation of the web-based survey, the web-based survey was piloted with twenty youths. The youths assessed the usability of the platform and provided recommendations with regards to the optimization of the web-based survey form. Logical checks for each question were performed. The web-based survey comprises of the following information:

\section{Socio-economic status}

Including age, gender, education status, occupation, and marital status.

\section{Health status}

The participants were asked to report whether individuals have had any acute diseases in the last 4 weeks, or any chronic diseases over the last 3 months. In addition, height, weight and body mass index information were also collated to determine whether participants were overweight/obese $\left(\geq 23.0 \mathrm{~kg} / \mathrm{m}^{2}\right)$. Health-related quality of life was measured by using EuroQol - five dimensions - five levels (EQ-5D-5 L) instrument. The descriptive system includes five domains: Mobility, Self-care, Usual activities, Pain/Discomfort and Anxiety/Depression with five levels of response: no problems, slight problems, moderate problems, severe problems, and extreme problems, giving 3125 health states with respective single indexes. To compute these indexes, the scoring for EQ-5D-5 L was based on the validated scoring done previously in a Thai study [17]. Moreover, we also measured the levels of stress in the last 30 days by using the Short-form Perceived Stress Scale (PSS). This tool assessed four items with a 5-point Likert scale, scoring from 0 (never) to 4 (very often). Total scores were from 0 to 16 , which higher scores mean higher levels of stress [18].

\section{Smartphone usage and preference}

We explored the amount of time individuals spent using their smartphone devices, and the functionalities that they had been using their smartphone for. In addition, we determined whether participants used their smartphone and smartphone applications/mobile services for health-related consultancy (including beauty counselling, nutrition counselling, disease prevention counselling, and disease treatment counselling) on the daily basis. We then examined how individuals were receptive towards the usage of smartphone related health applications and how satisfied they were towards the existing healthcare related applications.

\section{Statistical analysis}

A $p$-value of less than 0.05 was set as the level of statistical significance. We employed a Chi-squared test and Mann-Whitney test to explore the differences of smartphone receptiveness and preference between students and employees. Multivariate logistic regression was used to determine the factors associated with downloading mHealth apps among smartphone users.

\section{Results}

Data in Table 1 revealed that $83.4 \%$ of sample was students. A majority of participants were between 18 and 22 years old (64.8\%), had undergraduate education $(79.4 \%)$, were single (72.8\%), and living in a homestay (47.7\%).

The proportions of participants being overweight/ obesity, having acute diseases in the last 4 weeks, and chronic diseases in the last three months were 9.7\%, $10.1 \%$ and $19.8 \%$, respectively. $8.4 \%$ of the students and $16.4 \%$ of the employees were noted to be overweight/ obesity, and the difference between the two groups of participants was statistically significant $(p<0.01) .74 .6 \%$ reported that they have experienced anxiety or depressive symptoms; and $50.7 \%$ of the participants also reported experiencing pain and bodily discomfort. The mean of the EQ-5D index was 0.73 . The perceived stress scores of the employees were significantly higher than that of the students group $(p<0.05)$ (Table 2).

Table 1 Baseline demographics information of participants $(n=1028)$

\begin{tabular}{|c|c|c|c|c|c|c|}
\hline & \multicolumn{2}{|c|}{ Students } & \multicolumn{2}{|c|}{ Employees } & \multicolumn{2}{|l|}{ Total } \\
\hline & $\mathrm{n}$ & $\%$ & $\mathrm{~N}$ & $\%$ & $\mathrm{n}$ & $\%$ \\
\hline Total & 857 & 83.4 & 171 & 16.6 & 1028 & 100.0 \\
\hline \multicolumn{7}{|l|}{ Gender } \\
\hline Male & 335 & 39.1 & 89 & 52.1 & 424 & 41.3 \\
\hline Female & 522 & 60.9 & 82 & 47.9 & 604 & 58.7 \\
\hline \multicolumn{7}{|l|}{ Age groups } \\
\hline$<18$ & 38 & 4.4 & 0 & 0.0 & 38 & 3.7 \\
\hline $18-22$ & 555 & 64.8 & 9 & 5.3 & 564 & 54.9 \\
\hline$>22$ & 264 & 30.8 & 162 & 94.7 & 426 & 41.4 \\
\hline \multicolumn{7}{|l|}{ Education attainment } \\
\hline$\leq$ High school & 38 & 4.4 & 1 & 0.6 & 39 & 3.8 \\
\hline Vocation training & 12 & 1.4 & 7 & 4.1 & 19 & 1.9 \\
\hline College & 52 & 6.1 & 7 & 4.1 & 59 & 5.7 \\
\hline Undergraduate & 723 & 84.4 & 93 & 54.4 & 816 & 79.4 \\
\hline Postgraduate & 32 & 3.7 & 63 & 36.8 & 95 & 9.2 \\
\hline \multicolumn{7}{|l|}{ Marital status } \\
\hline Single & 631 & 73.6 & 117 & 68.4 & 748 & 72.8 \\
\hline Having spouse/partner & 226 & 26.4 & 54 & 31.6 & 280 & 27.2 \\
\hline \multicolumn{7}{|l|}{ Current living location } \\
\hline Homestay & 425 & 49.6 & 65 & 38.0 & 490 & 47.7 \\
\hline Dormitory & 117 & 13.7 & 7 & 4.1 & 124 & 12.1 \\
\hline Living with family & 232 & 27.1 & 84 & 49.1 & 316 & 30.7 \\
\hline Living with relatives & 73 & 8.5 & 12 & 7.0 & 85 & 8.3 \\
\hline
\end{tabular}


Table 2 Health Status and behaviors of Participants $(n=1028)$

\begin{tabular}{|c|c|c|c|c|c|c|c|}
\hline \multirow[t]{2}{*}{ Characteristics } & \multicolumn{2}{|c|}{ Students } & \multicolumn{2}{|c|}{ Employee } & \multicolumn{2}{|l|}{ Total } & \multirow[t]{2}{*}{$p$-value } \\
\hline & $n$ & $\%$ & $n$ & $\%$ & $\mathrm{n}$ & $\%$ & \\
\hline \multicolumn{8}{|c|}{ Having acute symptoms in the last 4 weeks } \\
\hline Yes & 88 & 10.3 & 16 & 9.4 & 104 & 10.1 & \multirow[t]{2}{*}{0.72} \\
\hline No & 769 & 89.7 & 155 & 90.6 & 924 & 89.9 & \\
\hline \multicolumn{8}{|c|}{ Having chronic diseases in the last 3 months } \\
\hline Yes & 172 & 20.1 & 32 & 18.7 & 204 & 19.8 & \multirow[t]{2}{*}{0.69} \\
\hline No & 685 & 79.9 & 139 & 81.3 & 824 & 80.2 & \\
\hline \multicolumn{8}{|l|}{ Overweight and obesity } \\
\hline Yes & 72 & 8.4 & 28 & 16.4 & 100 & 9.7 & \multirow[t]{2}{*}{$<0.01$} \\
\hline No & 785 & 91.6 & 143 & 83.6 & 928 & 90.3 & \\
\hline \multicolumn{8}{|l|}{ Health related quality of life } \\
\hline Having problem in mobility & 178 & 19.8 & 39 & 21.4 & 217 & 20.1 & 0.62 \\
\hline Having problem in self-care & 83 & 9.2 & 21 & 11.5 & 104 & 9.6 & 0.34 \\
\hline Having problem in usual activities & 198 & 22.1 & 37 & 20.3 & 235 & 21.8 & 0.61 \\
\hline Pain/Discomfort & 458 & 51.0 & 89 & 48.9 & 547 & 50.7 & 0.61 \\
\hline \multirow[t]{2}{*}{ Anxiety/Depression } & 678 & 75.5 & 128 & 70.3 & 806 & 74.6 & \multirow[t]{2}{*}{0.14} \\
\hline & Mean & SD & Mean & SD & Mean & SD & \\
\hline Height (cm) & 1.62 & 0.08 & 1.64 & 0.08 & 1.62 & 0.08 & $<0.01$ \\
\hline Weight (kg) & 52.56 & 8.90 & 55.45 & 9.39 & 53.05 & 9.04 & $<0.01$ \\
\hline Body mass index (kg/m2) & 19.94 & 2.20 & 20.57 & 2.34 & 20.04 & 2.23 & $<0.01$ \\
\hline EQ-5D index & 0.73 & 0.17 & 0.73 & 0.21 & 0.73 & 0.18 & 0.82 \\
\hline Perceived stress score & 6.64 & 2.11 & 6.27 & 2.19 & 6.58 & 2.13 & 0.03 \\
\hline
\end{tabular}

Among all the participants, $57.4 \%$ owned a smartphone. Only $14.1 \%$ of the smartphone users have used a health-related smartphone application, and most of these individuals downloaded the application for disease prevention (66.3\%). About $66.4 \%$ of the participants who owned these applications reported that health applications were useful and more than $92.8 \%$ reported being satisfied with the functionalities of the applications which they owned. Among application-users, nutrition counselling apps had the highest on-apps average time spent per day (18.6 min/day), following by beauty counselling (15.0 $\mathrm{min} /$ day) and diseases treatment counselling (15.0 min/day) (Table 3).

Data in Table 4 showed that $13.0 \%$ smartphone users had been overweight/obesity compared to only $5.3 \%$ of those who did not own smartphone. Similarly, $14.2 \%$ and $32.0 \%$ of smartphone owners had had acute symptoms in the last four weeks and chronic diseases in the last three months in comparison with only $4.6 \%$ and $3.4 \%$ of those not having smartphones, respectively. These differences were statistically significant $(p<0.05)$. Among overweight/obese individuals with smartphone, $24.7 \%$ and $32.5 \%$ used either a beauty or nutrition counselling application, respectively. Among smartphone users who have had acute symptoms, $42.9 \%$ and $39.3 \%$ used a disease prevention and treatment counselling application, respectively. Meanwhile, among participants suffering from chronic conditions, $23.8 \%$ and $21.1 \%$ respectively have used a disease prevention or a disease treatment counselling application (Table 4).

Among smartphone users, people who were employed $(\mathrm{OR}=15.46 ; 95 \% \mathrm{CI}=4.93-48.47)$ were more likely to download mHealth apps. Meanwhile, youths with higher EQ-5D index had a lower likelihood of downloading healthcare-related smartphone apps $(\mathrm{OR}=0.17 ; 95 \% \mathrm{CI}$ $=0.04-0.81$ ). We found no associations between having acute symptoms, chronic disease and body mass index with download mHealth apps (Table 5).

\section{Discussion}

Our current study highlights a low proportion of Vietnamese youths using healthcare related applications, with usage predominantly in disease prevention and beauty counseling applications. On the other hand, we found positive responses among youths using health-related applications, as most of them perceived the usefulness of apps as well satisfied with those apps. These results are important to show the acceptability of health-related 
Table 3 Usage of Smartphone Health \& Medical Applications and Attitudes towards Health/Medical applications among participants

\begin{tabular}{|c|c|c|c|c|c|c|c|}
\hline & \multicolumn{2}{|c|}{ Students } & \multicolumn{2}{|c|}{ Employees } & \multicolumn{2}{|l|}{ Total } & \multirow[t]{2}{*}{$p$-value } \\
\hline & $n$ & $\%$ & $n$ & $\%$ & $n$ & $\%$ & \\
\hline Using smartphone & 462 & 53.9 & 128 & 100.0 & 590 & 57.4 & \\
\hline Download health-related applications & 67 & 14.5 & 16 & 12.5 & 83 & 14.1 & 0.56 \\
\hline \multicolumn{8}{|l|}{ Type of applications } \\
\hline Beauty counselling & 34 & 50.7 & 13 & 81.3 & 47 & 56.6 & 0.04 \\
\hline Nutrition counselling & 29 & 43.3 & 11 & 68.8 & 40 & 48.2 & 0.06 \\
\hline Disease prevention counselling & 42 & 62.7 & 13 & 81.3 & 55 & 66.3 & 0.15 \\
\hline Disease treatment counselling & 34 & 50.7 & 10 & 62.5 & 44 & 53.0 & 0.27 \\
\hline Others & 9 & 13.4 & 1 & 6.3 & 10 & 12.0 & 0.57 \\
\hline \multicolumn{8}{|l|}{ Perceived benefits of health-related applications for health } \\
\hline Very useful & 46 & 68.7 & 9 & 56.3 & 55 & 66.4 & \multirow[t]{3}{*}{0.41} \\
\hline Neutral & 18 & 26.9 & 5 & 31.3 & 23 & 27.7 & \\
\hline Not useful & 3 & 4.5 & 2 & 12.5 & 5 & 6.0 & \\
\hline \multicolumn{8}{|l|}{ Satisfaction with mobile health applications/ services } \\
\hline Very satisfied & 35 & 52.2 & 5 & 31.3 & 40 & 48.2 & \multirow[t]{3}{*}{0.26} \\
\hline Neutral & 27 & 40.3 & 10 & 62.5 & 37 & 44.6 & \\
\hline Dissatisfied & 5 & 7.5 & 1 & 6.3 & 6 & 7.2 & \\
\hline Time to use mobile phone per day & Mean & SD & Mean & SD & Mean & SD & \\
\hline For calling (hour) & 0.8 & 1.0 & 1.2 & 1.4 & 0.9 & 1.1 & $<0.01$ \\
\hline For texting (hour) & 2.4 & 11.5 & 1.3 & 1.6 & 2.2 & 10.3 & 0.23 \\
\hline For others (game, watching movies,...) (hour) & 2.6 & 8.7 & 2.0 & 2.2 & 2.5 & 7.8 & 0.50 \\
\hline For beauty counselling (minute) $(n=47)$ & 13.2 & 27.0 & 21.0 & 34.2 & 15.0 & 28.2 & 0.49 \\
\hline For nutrition counselling (minute) $(n=40)$ & 19.2 & 68.4 & 18.0 & 36.0 & 18.6 & 60.0 & 0.93 \\
\hline For disease prevention counselling (minute) $(n=55)$ & 12.6 & 24.6 & 20.4 & 64.2 & 13.8 & 36.0 & 0.43 \\
\hline For disease treatment counselling (minute) $(n=44)$ & 16.2 & 37.8 & 11.4 & 16.8 & 15.0 & 33.0 & 0.63 \\
\hline
\end{tabular}

smartphone apps and the potential of mobile health intervention among youths in the future.

In this study, more than a half of sample owned a smartphone (57.4\%), which was higher compared to this rate in Vietnamese general population [16]. This proportion was lower than that in the developed countries, for example in Hong Kong (86\%) [19], South Korea (85\%), Japan (65\%) [20], or Netherland (90\%) [21]; but higher than that of other developing countries such as China (40\%) [20] and India (25\%) [22]. However, only a minor proportion of smartphone users in our study used medical- or health-related smartphone apps (14.1\%). This rate in our study was lower than what found in a study conducted on American adolescents, which found that $21 \%$ of smartphone owners used health-related mobile apps [23]. Still, our result was comparable to previous studies that reported a small proportion of smartphone users downloading mHealth apps [16, 24, 25]. The reason for this low rate might be due to the limited availability of healthcare or medical applications in Vietnamese as well as the fact that many of mHealth apps might not be available for free download, lowering the accessibility of the youths to them.

Notably, in our current study, despite the low rates of health-related apps downloaded, among smartphone owners who have downloaded mHealth apps, we have found a slightly higher percentage of individuals who preferred to download and use disease prevention apps compared to other apps. This was consistent with previous surveys, which indicated that fitness, weight management, or tracking health apps were preferred most [26, 27]. Moreover, users seemed to be well-adapted with mHealth apps when more than half of the sample perceived the usefulness of apps and satisfied with these apps. This result is more positive than finding from a previous study conducted in the USA [24], implying the acceptability of youths and adolescents regarding mHealth apps.

In prior studies, education, gender, and age were found as significant predictors of the usage of mHealth apps $[12,19,23,26,28-30]$, but such relationships were not found in this study. This might due to the relative homogeneousity of these characteristics. Nonetheless, 
Table 4 Usage of Smartphone Health \& Medical Applications according to health status

\begin{tabular}{|c|c|c|c|c|c|}
\hline \multirow[t]{3}{*}{ Health status } & \multicolumn{4}{|c|}{ Having smartphone } & \multirow[t]{3}{*}{$p$-value } \\
\hline & \multicolumn{2}{|l|}{ Yes } & \multicolumn{2}{|l|}{ No } & \\
\hline & $\mathrm{N}$ & $\%$ & $\mathrm{n}$ & $\%$ & \\
\hline Total & 590 & 57.4 & 438 & 42.6 & \\
\hline \multicolumn{6}{|l|}{ Obesity and overweight } \\
\hline No & 513 & 87.0 & 415 & 94.8 & \multirow[t]{4}{*}{$<0.01$} \\
\hline Yes & 77 & 13.0 & 23 & 5.3 & \\
\hline - Using beauty counselling app & 19 & 24.7 & & & \\
\hline • Using nutrition counselling app & 25 & 32.5 & & & \\
\hline \multicolumn{6}{|l|}{ Having acute symptoms in the last four weeks } \\
\hline No & 506 & 85.8 & 418 & 95.4 & \multirow[t]{4}{*}{$<0.01$} \\
\hline Yes & 84 & 14.2 & 20 & 4.6 & \\
\hline - Using disease prevention counselling app & 36 & 42.9 & & & \\
\hline - Using disease treatment counselling app & 33 & 39.3 & & & \\
\hline \multicolumn{6}{|l|}{ Having chronic diseases in the last three months } \\
\hline No & 401 & 68.0 & 423 & 96.6 & \multirow[t]{4}{*}{$<0.01$} \\
\hline Yes & 189 & 32.0 & 15 & 3.4 & \\
\hline - Using disease prevention counselling app & 45 & 23.8 & & & \\
\hline - Using disease treatment counselling app & 40 & 21.2 & & & \\
\hline
\end{tabular}

the finding indicated that among smartphone users, individuals who were already employed had a higher likelihood of downloading mHealth apps compared to students. We supposed that employed people might have a higher level of education compared to those who were students; hence, they might have better awareness in how personal health condition impact work performance and general living quality, which promoted them to seek health information, using technological advances such as the Internet or the smartphone. In literature, educational attainment is a significant predictor of health seeking behaviors among young people, such as seeking for further health-related information [28, 31-33].

In this study, despite significant differences between people with and without smartphones regarding health status, associations between having the illness, body mass index, stress and mHealth apps usage were not found in multivariate regression models. This is different from results of previous studies in other countries, which indicated that youths and adolescents having

Table 5 Factors associated with the use of mhealth apps among smartphone users

\begin{tabular}{|c|c|c|c|c|}
\hline \multirow{2}{*}{$\begin{array}{l}\text { Characteristics } \\
\text { Age }\end{array}$} & \multirow{2}{*}{$\frac{\text { Odds Ratio }}{0.95}$} & \multirow{2}{*}{$\frac{p \text {-value }}{0.24}$} & \multicolumn{2}{|c|}{ 95\% Confident interval } \\
\hline & & & 0.87 & 1.03 \\
\hline Gender (Male vs Female) & 0.81 & 0.48 & 0.45 & 1.46 \\
\hline Occupations (Employees vs Students) & 15.46 & 0.00 & 4.93 & 48.47 \\
\hline \multicolumn{5}{|l|}{ Education attainment (vs < High school) } \\
\hline - High school & 3.67 & 0.31 & 0.30 & 45.24 \\
\hline$\cdot>$ High school & 2.77 & 0.34 & 0.34 & 22.65 \\
\hline Marital status (Having spouse/partner vs Single) & 1.29 & 0.43 & 0.69 & 2.43 \\
\hline Having acute symptoms (Yes vs No) & 1.26 & 0.62 & 0.51 & 3.15 \\
\hline Having chronic diseases (Yes vs No) & 1.11 & 0.76 & 0.57 & 2.13 \\
\hline \multicolumn{5}{|l|}{ Body mass index (vs Normal) } \\
\hline - Underweight & 0.72 & 0.46 & 0.30 & 1.72 \\
\hline - Overweight/Obesity & 1.74 & 0.31 & 0.60 & 5.06 \\
\hline Perceived stress score & 0.91 & 0.14 & 0.80 & 1.03 \\
\hline EQ-5D index & 0.17 & 0.03 & 0.04 & 0.81 \\
\hline
\end{tabular}


chronic illness were more likely to use mHealth apps to improve their conditions $[24,26]$. We assumed that when our respondents suffered from health issues, they tended to visit health facilities rather than downloading and using healthcare apps. Nonetheless, we observed that among smartphone owners, youths having high HRQOL were less likely to download mHealth apps, in other words, people with lower HRQOL had a higher likelihood of using health-related mobile apps. It appears that mHealth apps were used to promote better health status and then improve youths' quality of life. Therefore, developing mHealth apps that support youths and adolescents in keeping healthy lifestyles and improve their quality of life seems to be reasonable, which can promote the use of mHealth apps in these populations in Vietnam.

There are some limitations of our study which we do need to consider. Our study was a cross-sectional study; therefore, we were not able to track how the attitudes towards health-related smartphone applications would change over time. Secondly, most of the information that we acquired from the sample was self-reported information which may subjected to recall bias as participants might not report their smartphone usage accurately. The perspectives that we have acquired might not be generalizable to the rest of the Vietnamese young population, as the socio-demographics of youths in the general population might be different.

\section{Conclusion}

In conclusion, this study highlighted a low rate of mHealth apps utilization among online Vietnamese youths and adolescents but a high acceptance of individuals who already used these apps. Developing mHealth apps or interventions towards disease prevention and quality of life improvement could be feasible to proliferate the benefits of such apps in youths and adolescents in Vietnam. Further researches should be conducted to optimize the contents and interfaces of mHealth apps that meet the needs of these populations.

\section{Abbreviation}

RDS: Respondent-driven sampling technique

\section{Acknowledgements}

We would like to express our deepest gratitude to all contributors for this survey.

\section{Availability of data and materials}

The data that support the findings of this study are available from the Vietnam Authority of HIV/AIDS Control but restrictions apply to the availability of these data, which were used under license for the current study, and so are not publicly available. Data are however available from the authors upon reasonable request and with permission of Vietnam Authority of HIV/AIDS Control.

\section{Authors' contributions}

TTTD, MDL, BXT, CTN, TVN, RH, MZ, LHN, CAL, RCMH, MWBZ: Developed the outline and contributed to analyses, interpreted results, and wrote the first and final drafts of the manuscript. TTTD, MDL, NVT, LHN, TDT, HTL, HDN:

Contributed to analyses, interpreted results, and wrote the manuscript. BXT CTN, LHN, CAL, RCMH, MWBZ, HTL, HDN: Designed the study and collected data and all authors: Read and approved the final manuscript.

\section{Ethics approval and consent to participate}

Proposal of this research was approved by IRB of the Vietnam Authority of HIV/AIDS Control. Participants were asked to give E-informed consent and were informed that they could withdraw at anytime. Their contact information was coded and ensured to be confidential. In case respondents were under 16, we required written informed parental consent e-form to be filled prior to the survey.

\section{Competing interests}

The authors declare that they have no competing interests.

\section{Publisher's Note}

Springer Nature remains neutral with regard to jurisdictional claims in published maps and institutional affiliations.

\section{Author details}

${ }^{1}$ Institute for Preventive Medicine and Public Health, Hanoi Medical University, Hanoi, Vietnam. ${ }^{2}$ Department of Hospital Quality Management, Vietnam National Cancer Hospital, Hanoi, Vietnam. ${ }^{3}$ Bloomberg School of Public Health, Johns Hopkins University, Baltimore, MD, USA. ${ }^{4}$ Institute for Global Health Innovations, Duy Tan University, Da Nang, Vietnam.

${ }^{5}$ Department of Hepatobiliary Surgery, Viet-Duc Hospital, Hanoi, Vietnam. ${ }^{6}$ Department of Psychological Medicine, Yong Loo Lin School of Medicine, National University of Singapore, Singapore, Singapore. ${ }^{7}$ Biomedical Global Institute of Healthcare Research \& Technology (BIGHEART), National University of Singapore, Singapore, Singapore. ${ }^{8}$ School of Medicine and Pharmacy, Vietnam National University, Hanoi, Vietnam.

Received: 6 September 2017 Accepted: 31 May 2018

Published online: 19 June 2018

\section{References}

1. Boulos MNK, Wheeler S, Tavares C, Jones R. How smartphones are changing the face of mobile and participatory healthcare: an overview, with example from eCAALYX.BioMedical Engineering OnLine. 2011;10:24. https://doi.org/ 10.1186/1475-925X-10-24.

2. Portal TS: Number of smartphone users* ${ }^{*}$ worldwide from 2014 to 2019 (in millions). 2016

3. Number of apps available in leading app stores as of March 2017. https:// www.statista.com/statistics/276623/number-of-apps-available-in-leadingapp-stores/. Accessed 30 Mar 2017.

4. IDC. Always ConnectedHow Smartphones And Social Keep Us Engaged. Massachusets: IDC; 2013.

5. Boulos MNK, Brewer AC, Karimkhani C, Buller DB, Dellavalle RP.Mobile medical and health apps: state of the art, concerns, regulatory control and certification.Online Journal of Public Health Informatics. 2014;5(3):229. https://doi.org/10.5210/ojphi.v5i3.4814.

6. Franko Ol, Tirrell TF. Smartphone app use among medical providers in ACGME training programs. J Med Syst. 2012;36(5):3135-9.

7. ACMA. Mobile apps: putting the 'smart' in smartphones. In: ACMA research snapshots; 2013

8. Aldiss S, Baggott C, Gibson F, Mobbs S, Taylor RM. A critical review of the use of technology to provide psychosocial support for children and young people with long-term conditions. J Pediatr Nurs. 2015;30(1):87-101.

9. Kenny R, Dooley B, Fitzgerald A. Developing mental health mobile apps: exploring adolescents' perspectives. Health Inform J. 2016;22(2):265-75.

10. Sanchez-Rodriguez E, de la Vega R, Castarlenas E, Roset R, Miro J. AN APP for the assessment of pain intensity: validity properties and agreement of pain reports when used with young people. Pain Med. 2015;16(10):1982-92.

11. O'Malley G, Dowdall G, Burls A, Perry IJ, Curran N. Exploring the usability of a mobile app for adolescent obesity management. JMIR mHealth uHealth. 2014;2(2):e29 
12. Majeed-Ariss R, Hall AG, McDonagh J, Fallon D, Swallow V. Mobile Phone and Tablet Apps to Support Young People's Management of Their Physical Long-Term Conditions: A Systematic Review Protocol. Eysenbach G, ed. JMIR Research Protocols. 2015;4(2):e40. https://doi.org/10.2196/resprot.4159.

13. Svensson A, Larsson C. A mobile phone app for dietary intake assessment in adolescents: an evaluation study. JMIR mHealth uHealth. 2015;3(4):e93.

14. Lopez C, Ramirez DC, Valenzuela Jl, et al. Sexual and reproductive health for young adults in Colombia: teleconsultation using mobile devices. Eysenbach G, ed. JMIR mHealth and uHealth. 2014;2(3):e38. https://doi.org/ $10.2196 /$ mhealth.2904

15. Motivating patients to use smartphones health apps. http://www.consumerhealth.com/motivating-patients-to-use-smartphone-health-apps/. Accessed 2 Apr 2017.

16. Growing Smartphone Ownership in Vietnam Opens Door For Mobile Marketers. https://www.forbes.com/sites/davisbrett/2016/02/18/growingsmartphone-ownership-in-vietnam-opens-door-for-mobile-marketers/ \#2d2a8b2d34ed. Accessed 2 Apr 2017.

17. Tran BX, Ohinmaa A, Nguyen LT. Quality of life profile and psychometric properties of the EQ-5D-5L in HIV/AIDS patients. Health Qual Life Outcomes. 2012;10

18. Karam F, Berard A, Sheehy O, Huneau MC, Briggs G, Chambers C, Einarson A, Johnson D, Kao K, Koren G, et al. Reliability and validity of the 4-item perceived stress scale among pregnant women: results from the OTIS antidepressants study. Res Nurs Health. 2012;35(4):363-75.

19. Kwok SWH, Lee PH, Lee RLT. Smart device use and perceived physical and psychosocial outcomes among Hong Kong adolescents. Theall KP, Johnson CC, eds. Int J Environ Res Public Health. 2017;14(2):205. https://doi.org/10. 3390/ijerph14020205.

20. Mak KK, Lai CM, Watanabe H, Kim DI, Bahar N, Ramos M, Young KS, Ho RC, Aum NR, Cheng C. Epidemiology of internet behaviors and addiction among adolescents in six Asian countries. Cyberpsychol Behav Soc Network. 2014;17(11):720-8.

21. Statistiek CBvd. Mobile Internet Use Continues to Grow. Den Haag: Statistics Netherlands Press Release; 2013.

22. Smartphone users around the world - Statistics and Facts. https://www.gogulf.com/blog/smartphone. Accessed 2 Apr 2017.

23. Wartella E, Rideout V, Montague H, Beaudoin-Ryan L, Lauricella A. Teens, health and technology: a National Survey. Media and Communication. 2016; 4(3):13-23. https://doi.org/10.17645/mac.v4i3.515.

24. Chan A, Kow R, Cheng JK. Adolescents' perceptions on smartphone applications (apps) for health management. J Mobile Technol Med. 2017; 6(2):47-55.

25. Majeed-Ariss R, Baildam E, Campbell M, et al. Apps and adolescents: a systematic review of adolescents' use of mobile phone and tablet apps that support personal Management of Their Chronic or long-term physical conditions. J Med Internet Res. 2015;17(12):e287. https://doi.org/10.2196/jmir.5043.

26. Krebs P, Duncan DT. Health app use among US mobile phone owners: a National Survey. Eysenbach G, ed. JMIR mHealth uHealth. 2015;3(4):e101. https://doi.org/10.2196/mhealth.4924.

27. Fox S. Mobile health 2012. In: Pew Internet \& American Life Project. Washington: Pew Research Center. p. 2012.

28. Cutler DM, Lleras-Muney A. Understanding differences in health behaviors by education. J Health Econ. 2010;29(1):1-28

29. Carroll JK, Moorhead A, Bond R, LeBlanc WG, Petrella RJ, Fiscella K. Who uses mobile phone health apps and does use matter? A secondary data analytics approach. J Med Internet Res. 2017;19(4)

30. Alkhatlan HM, Rahman KF, Aljazzaf BH. Factors affecting seeking health-related information through the internet among patients in Kuwait. Alexandria J Med. 2017. https://doi.org/10.1016/j.ajme.2017.05.008

31. Margolis R. Educational differences in healthy behavior changes and adherence among middle-aged Americans. J Health Soc Behav. 2013;54(3):353-68.

32. Ireland loPHi: Health Impacts of Education - a review. The Institute of Public Health in Ireland. Dublin 2, Ireland; 2008

33. Grundy J, Annear P. Health-seeking behaviour studies: a literature review of study design and methods with a focus on Cambodia. Australia: Nossal Institute for Global Health, The University of Melbourne; 2010.

\section{Ready to submit your research? Choose BMC and benefit from:}

- fast, convenient online submission

- thorough peer review by experienced researchers in your field

- rapid publication on acceptance

- support for research data, including large and complex data types

- gold Open Access which fosters wider collaboration and increased citations

- maximum visibility for your research: over $100 \mathrm{M}$ website views per year

At BMC, research is always in progress.

Learn more biomedcentral.com/submissions 